\title{
Individuals taking combination therapies for HIV or AIDS faced barriers to remaining in, or returning to work
}

Maticka-Tyndale E, Adam BD, Cohen JJ. To work or not to work: combination therapies and HIV.Qual Health Res 2002;12:1353-72

\section{QUESTION: What are the labour force experiences of people living with HIV or AIDS who are taking combination therapies?}

Design

Qualitative description.

\section{Setting}

Windsor and Essex County region of Ontario, Canada.

\section{Participants}

35 people $\geq 18$ years of age $(89 \%$ men) who had tested positive for HIV, were taking combination therapies, and lived in or received AIDS services in Essex County were identified by the local HIV Care Program and AIDS Service Organization. Two thirds of participants were 30-39 years of age. Participants had been aware of their HIV positive status for $<2$ to $>5$ years.

\section{Methods}

Individual, semistructured, indepth interviews were done between 1999 and 2000. Open ended questions addressed areas including treatment patterns, taking medications, symptom management strategies, work activities, relationships, life changes, and future plans. Interviews generally lasted 1-1.5 hours. Data analysis involved identifying clusters of participants by comparable illness and labour force experiences, linking medical indicators with illness experiences, and placing labour force experiences within the contexts of illness experiences, labour market, workplace, and health and social service systems. Participants reviewed a draft of the analysis, and a focus group was used to establish trustworthiness of data.

\section{Main findings}

2 major themes, time living with HIV and symptomatology, described participants' personal illness experiences. Participants had side effects ranging from none to serious. Symptom alleviation was key to managing HIV. Participants clustered into 4 groups: asymptomatic, improved, less severe, and more severe symptoms; these groups coincided with distinct medical markers related to $\mathrm{CD}_{4}$ count, viral load, AIDS defining conditions, and Karnofsky score.

Participants' labour force experiences since diagnosis ranged from continuous full time, full time with a break because of HIV related illness, part time, and unemployed. Unemployment was usually because of severe HIV related illness, serious symptoms, or because employers or coworkers made participants feel unwelcome in the workplace. Those with less severe symptoms often wanted to return to work; those with more severe (often debilitating) symptoms generally did not. Many participants in the asymptomatic, improved, and less severe groups had full time work. Some in the less severe group had to make a specific commitment to remain in or return to the labour force in order to obtain full time work.

Returning to work after an illness related break required a specific decision and commitment, which was an important sign of overcoming poor health and re-establishing independence. For asymptomatic and less severe groups, a break in employment often related to a purposeful "rebalancing" of life and priorities. Participants faced multiple barriers when returning to work, some of which were unique to persons with HIV. Barriers included finding an appropriate job; considering income, cost of drugs, and uninsured health services; dealing with symptoms and therapeutic regimens while working; and disclosure and threats of discrimination.

\section{Conclusions}

For persons living with HIV or AIDS who were taking combination therapies, labour force participation had a distinct relation to illness experience and the structural context of workplace, labour market, and health and social service system. Barriers to returning to or remaining in the labour force were numerous and required a specific commitment to overcome them.

\section{COMMENTARY}

The study by Maticka-Tyndale is an important contribution to the international literature and a unique contribution to the Canadian literature. It shows the challenges that persons who are HIV positive with advanced disease face in remaining in or returning to the workforce. This study points to a key role nurses can play in supporting individuals to seek early counselling and HIV testing, careful monitoring of health, and timely and effective antiretroviral therapy prescribed and monitored by an HIV experienced team of health professionals. ${ }^{1}$

Health Canada estimates that in 2002, one third of Canadians who were HIV positive $(15000)$ were unaware of their HIV positive status. $^{2}$ Because HIV has a well understood biological trajectory, timely intervention with antiretroviral therapy makes HIV a manageable chronic illness in which asymptomatic or improved periods can be extended. ${ }^{3}$ This increases the possibility of remaining in the work force.

This study shows the need for nurses to advocate for access to rehabilitation services and more flexible responses to chronic illness in government policy and by employers. It offers nurses direction for supporting individuals in "purposeful rebalancing of life and priorities" throughout the trajectory. It does not consider the additional challenges faced by persons who are HIV positive and recovering from addiction, receiving antiretroviral therapy, and wishing to seek paid employment. Currently, 23\% of Canadians with newly diagnosed HIV are coping with an

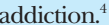

Irene Goldstone, RN, MSc

Director, Professional Education and Care Evaluation British Columbia Centre for Excellence in HIV/AIDS St Paul's Hospital, Vancouver, British Columbia, Canada

1 Kitahata MM, Van Rompaey SE, Dillingham PW, et al.J Gen Intern Med 2003;18:95-103.

Division of HIV/AIDS Epidemiology and Surveillance. Prevalent HIV infections in Canada: up to one-third may not be diagnosed. HIV/AIDS Epi Update 2002. Ottawa: Centre for diagnosed. HIV/AIDS Epi Update 2002. Ottawa: Centre for April 2003. http://www.hc-sc.gc.ca/pphb-dgspsp/publicat/ epiu-aepi/hiv-vih/hivtest e.html

3 Hogg RS, Yip B, Chan KJ, et al. JAMA 2001;286:2568-77.

4 Division of HIV/AIDS Epidemiology and Surveillance HIV/ AIDS among injecting drug users in Canada. HIV/AIDS Epi AIDS among injecting drug users in Canada. HIV/AIDS Epi Update 2003. Ottawa: Centre for Infectious Disease Prevenwww.hc-sc.gc.ca/pphb-dgspsp/publicat/epiu-aepi/ hiv-vih/idus_e.html 